\title{
Aesthetic Experience and Digital Culture: New Flows in The Space of Art Exhibition
}

\author{
Keywords \\ Aesthetic Experience; Art; Consumption; Digital culture; Photography.
}

Artistic institutions are traditionally places of cultural and social memory reverberation. Such spaces have a character of institutionalisation of the cultural market. Contemporary works of art and the exhibition format are factors that shape the possibilities of consumption and experience from visitors within these spaces. By taking advantage of the artifices of their time, art and artists appropriate new digital Technologies, digital culture contextualizes this movement, interweaving new paradigms in the exhibition spaces of museums, galleries and cultural centres. It is clear that the artistic production that involves digital media at some level creates increasingly subjective and hybrid paths between machine and human in the processes. This occurs not only in the scope of raw material and in the production of their poetics and narratives, but also in every present social context, of consumption, access, and dissemination of artistic works. In the last 10 years there has been a growing number of public in cultural institutions in Brazil (data from IPEA - Institute for Applied Economic Research), this curve does not resemble any increase in investment in public policies, improvement in education or culture. This rate of increase in visitors to cultural spaces is like the increase in access to mobile devices and use of the internet and social networks, perhaps, at some level, it shows that internet access and digital culture may be enabling an environment of spontaneous dissemination for the artistic market in Brazil.
With the advent of smartphones and the constant use of this technology in various moments of leisure and work, the habit of taking a picture from any work of art has become something normalised in institutions. This process can create different media flows that reformulate the visitor's experience in front of the exhibition space. In this way, the traditional and passive spectator subject is mixed with the user subject present in digital culture, with its agency potential and sharing capacity. Although these photographs present themselves in society as a cultural product, their visualisation and distribution extend to a computational level. This master's research project proposes to establish dialogues between the field of communication and the arts, especially digital culture, and aesthetic experience. The object of study is the production of photographic images made by visitors to cultural exhibitions through smartphones and shared on the Instagram social network. Through the use of artificial intelligence, it will be possible to analyse hundreds of images from the Instagram social network that were taken at the Banco do Brasil Cultural Centre, located in the city of Rio de Janeiro, Brazil (Brazilian institution with the highest number of visitors in the last 5 years). This qualitative and quantitative analysis enables a reflection on the contemporary media character present in art exhibition spaces and the observation of new experiences between public, work, and digital culture. 